\title{
Phytoplankton and the physical environment in the Helgoland region
}

\author{
Max Gillbricht \\ Biologische Anstalt Helgoland; Notkestr. 31, D-22607 Hamburg, Germany
}

\begin{abstract}
The phytoplankton development in the waters around Helgoland can be described as a function of the physical environment (derivates of the temperature). This is a consequence of the fundamental annual cycle regulated by the sun and, respectively, by dependent components. This simple statement can only give good results if the turbulent transport processes in the transition zone are considered. Investigations are impeded by the fact that the multiplication rate of the organisms is almost counterbalanced by losses that take place during the long lasting bloom. This situation is a product of the regional hydrography, whereby small changes in the environment on varied time scales influence the development of the population fundamentally. This becomes particularly clear when the numerical results of the exponential growth are examined. The dynamics of this complicated process can be seen best in the great annual differences of the phytoplankton maxima.
\end{abstract}

\section{INTRODUCTION}

Life on earth has, from the beginning, been influenced by numerous climatic changes and fluctuations. These alterations take place on differing time scales, some of which are far beyond the ken of man and others are significant but small-scale (see below). Therefore, "tendencies" discovered in our "long-term" series may be within the normal range of deviation. This fact can easily be grasped when we compare our data from the station near Helgoland with the hydrographical measurements taken over far longer periods, or with the reports concerning phytoplankton blooms in the older literature, or with the fluctuations of fish stocks during the centuries (Gillbricht, 1983; most citations in the "Literature cited" of this present paper include a number of pertinent literature).

We know on the other hand that the life cycle of plants and animals has a pronounced annual component, especially in more northern latitudes. This finding has been a well-known fact since prehistoric times, and it was generally accepted that this had something to do with the sun. If this is correct - and there is no argument against it then we may state that (the annual cycle of) phytoplankton is primarily regulated by the sun or indirectly by the physical environment.

This statement restricts the assumption of Brandt $(1899,1902)$ with regard to the importance of nutrients (especially nitrogen) as a normal situation, and, indeed, no limitation of the growth rate by these substances (maybe with the exceptions of $\mathrm{Si}$ ) can be observed in this region (Gillbricht, 1988), as assumed also by Radach \& Bohle-Carbonell (1990). 
What do we know, however, about the growth-promoting physical conditions for phytoplankton?

The direct influence of the sun: (a) Production should be more or less proportional to day length. (b) Light intensity influences this system in a complicated way. Phytoplankton organisms are "shadow plants" that dislike direct sunlight. They grow, therefore, further from the surface in bright conditions, but nearer the surface in dim light, whereby the flagellates may actively swim up and down, influenced by the turbidity of the water (Gillbricht, 1983).

The indirect influe nce of the sun: (a) The speed at which the warming up of the water takes place has something to do with the density stratification and the vertical turbulence, an essential component for the phytoplankton (Gran \& Braarud, 1935). (b) It should be pointed out that all meteorological processes and consequences (storms, currents, waves and so on) are ultimately produced by the sun; and in the case of tidal effects, the sun is highly supported by the moon.

Besides the direct influence of the sun as a function of season and latitude, turbulence and turbidity (the latter in shallow waters may be affected by turbulence; Gillbricht, 1962) regulate the effective growth rate of phytoplankton, as formulated by Sverdrup (1953). When investigating this problem by means of measurements, the crucial question is how to determine this mixing process, which is normally not known and not seen directly. This difficulty in connection with phytoplankton development was investigated in a harbour basin in Wilhelmshaven due to the initiative of A. Bückmann (Gillbricht, 1955). The harbour basin was filled with an extremely nutrient-rich mixture of seawater and brownish moor water. These "yellow substances" diminished the light intensity in the water enormously, with the result that there was an euphotic zone of a few metres only. Under these conditions, absolutely "normal" phytoplankton cycles with exponential increases and decreases and with pronounced spring blooms could be observed. There was a major increase in the cell numbers of the diatom Skeletonema costatum in March/April 1951. Suddenly this development stopped, and an even more pronounced decrease started. Both phases were described best by two logarithmic straight lines. Nothing could be said about what happened in the crossing region of these two lines, because no samples could be taken during these days as a consequence of a gale; and this gale was also the reason for the breakdown of the population. The water column, previously stabilized by a great vertical density gradient, was completely mixed in the upper layer by the rough weather, thus facilitating and practically also indicating great vertical turbulence. A similar development has been observed in other years. In situations such as these, the plankton is regulated by single special events, and its development cannot, therefore, be described correctly by smoothed curves.

The daily increase of approximately $15 \%$ of the diatom stock, as observed in the harbour basin, was also found during the bloom season in the central North Sea in 1976 (Gillbricht, 1988).

\section{MATERIAL AND METHODS}

A permanent station has existed near Helgoland since 1873 for hydrography, and since 1962 for phytoplankton and chemistry. More technical details in connection with these investigations are given by Gillbricht (1988). During the second half of 1982, the 
salinity values could not be used, and the respective calculations were made by interpolation.

The intention of this study is to find out the interconnections between the phytoplankton and the physical surroundings. From a statistical point of view, the situation is poor, especially in the case of time series. Only the negative findings can be considered sufficiently trustworthy (Gillbricht, 1988). This fact reduces the quality of any results.

A time span of seven years (1980 to 1986) with highly differing plankton amplitudes was chosen, with an overhang of half a year at both ends to exclude boundary effects. A description of the annual cycles (temperature $\left[{ }^{\circ} \mathrm{C}\right]$, salinity $\left[10^{-3}\right]$, phosphate-P, inorganically bound nitrogen $\left[\mu \mathrm{g}-\mathrm{atom} \cdot \mathrm{dm}^{-3}\right]$, diatoms and the other phytoplankton organisms - first and foremost the flagellates $-\left[\mu \mathrm{g} \mathrm{C} \cdot \mathrm{dm}^{-3}\right]$ ) can be reasonably made by cyclical functions only. Thus, the course of every component is described by four sinus curves, optimized by approximation. The problems involved in such a procedure are discussed in Gillbricht (1988).

The plankton organisms are distributed in all dimensions (space and time) on an exponential scale. This fact needs the same transformation for the calculations (Gillbricht, 1988). Therefore, the respective equations are approximated, not directly with the quantity of the plankton carbon $(C)$, but with $\log (C)$. This procedure entails some problems:

(a) In the case of very low values (random distribution), the logarithms are uncertain; and "zero" must be substituted by a small number (diatoms).

(b) Returning from the logarithmic system to the numerical one gives results that are too meagre. Therefore, a correction is calculated by dividing "the sum of all observations" by "the sum of all recalculated numbers". The factor reached in this way is approximately two, differing from equation to equation, and is higher for the diatoms with a more uneven distribution than for the flagellates.

By means of these smoothing procedures, acceptable results are acquired. The phytoplankton curves (Fig. 1) demonstrate clearly the variations from year to year, the small diatom numbers in winter time and an increased multiplication rate in spring as compared with the flagellates.

In order to evaluate the dynamic processes one needs to compensate for the permanent water exchange, which is seen in the continuous salinity fluctuations with disturbed annual cycles (Fig.2). Measurements can only give an idea of the true development in time if they are carried out in the same water body. As this is not possible, we should try to compensate for this defect by calculations. The best way to do this is to describe the "water body" by salinity. However, even though this method may be useful, it can never overcome all the problems (Gillbricht, 1988).

To introduce salinity into the equations developed above, all constants were expanded by two further terms, by $S$ (salinity) and $S^{2}$. It can be seen after optimization of these systems that the mean growth rates $(S=31$; the salinity normally used in this investigation), from minimum to maximum, are low compared with those in the harbour basin and in the North Sea (see above), or even with the production (Gillbricht, 1988). The daily increase is roughly $0.9 \%$ for the flagellates and $3.1 \%$ for the diatoms, and the numerical differences of the maximal concentrations are impressive in contrast to the small fluctuations of the respective increases. The factor between these maxima of neighbouring years varies for flagellates between 1.3 and 1.9, for diatoms between 1.3 


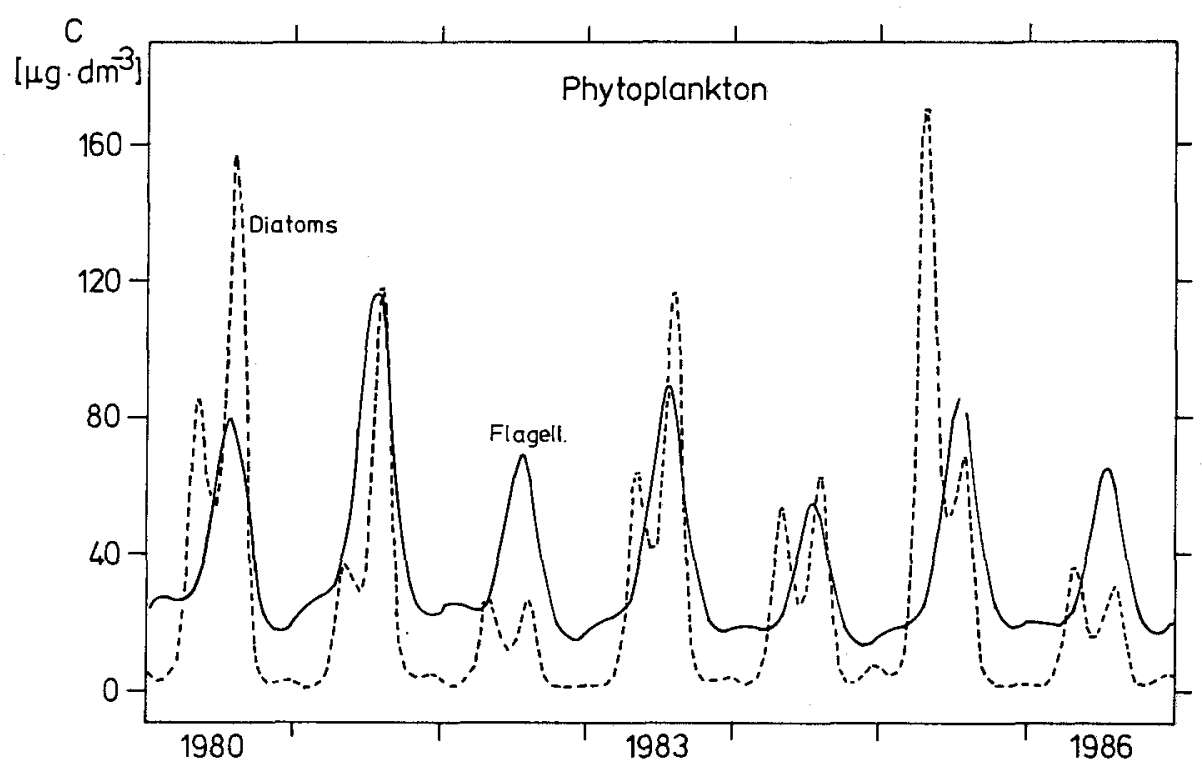

Fig. 1. Helgoland Roads 1980-1986: stocks of flagellates and diatoms given as C (carbon); flagellates: $\mathrm{N}=$ number of observations $=1948_{i} \mathrm{R}=$ multiple correlation coefficient $=0.684_{i}$ diatoms: $N=1948 ; R=0.653$

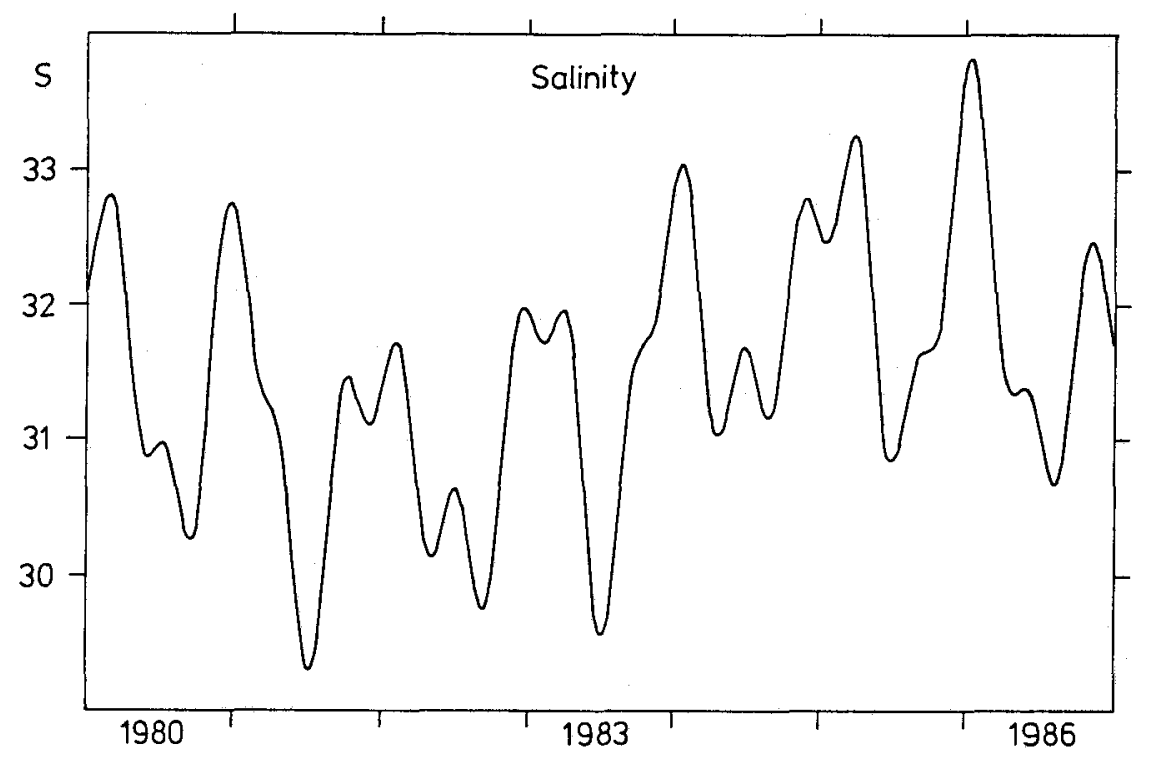

Fig. 2. Helgoland Roads 1980-1986: course of salinity; $N=1831 ; R=0.687$ 
and 4.3 and for the phytoplankton as a whole between 1.0 and 2.8. This discrepancy between stock and growth can easily be explained:

(a) In the case of physical regulation of the growth rate, the maximum concentration is directly proportional to the initial minimum concentration of the stock, if we exclude a reasonable influence of the phytoplankton upon the turbidity of the water (self shading) or any other feedback.

(b) The results of an exponential growth rate are highly influenced by the duration of the growth phase especially when recalculated in a numerical system, and this period is long in this region (six months; Gillbricht, 1988).

(c) Therefore, small differences in the exponential increases and decreases will have major effects on the stocks; for instance, a doubling of a population over a period of six months needs a daily growth rate of $0.38 \%$. This fact hinders or, at least, hampers a good quantitative description of the system.

The equations developed allow a separation of the effects of time and salinity upon the phytoplankton (Fig. 3). The time course of the stock for $S=31$ has, in a logarithmic system, distinctly greater amplitudes than the salinity curve. The latter was calculated for the time of the phytoplankton maximum in 1983, under the condition of changing (mean) salinity during the course. Thus, it includes the annual cycle of the salinity, which is not realistic for a fixed time of the year, and it excludes on the other hand the extreme values eliminated by the smoothing.

Calculating the phytoplankton stock for different salinities demonstrates that the quantity increases with decreasing salinity during the vegetation period (Fig. 4 ; Gillbricht, 1988), indicating better growth conditions and demonstrating different logarithmic gradients with respect to salinity from year to year.

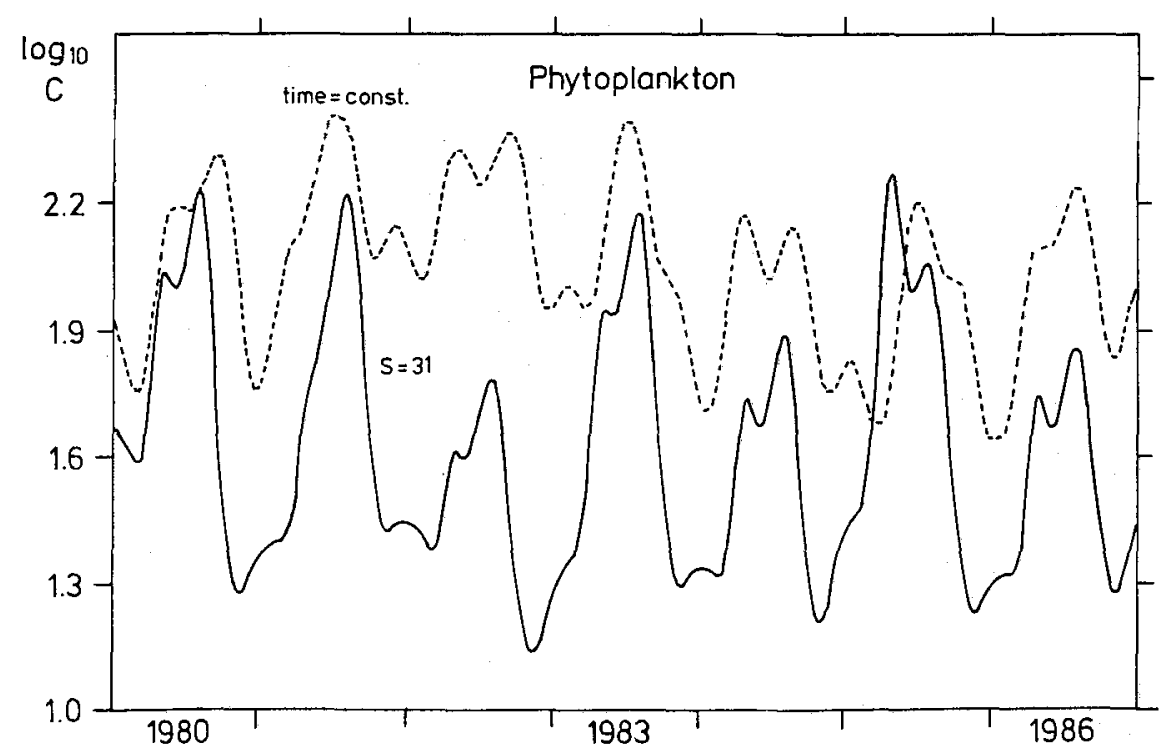

Fig. 3. Helgoland Roads 1980-1986: logarithms of the phytoplankton stock calculated for a constant salinity ( $S=31$ ) as a function of time and for a constant time (maximum 1983) as a function of the mean salinity curve; flagellates: $N=1830_{i} R=0.761_{\text {; }}$ diatoms: $N=1830 ; R=0.695$ 


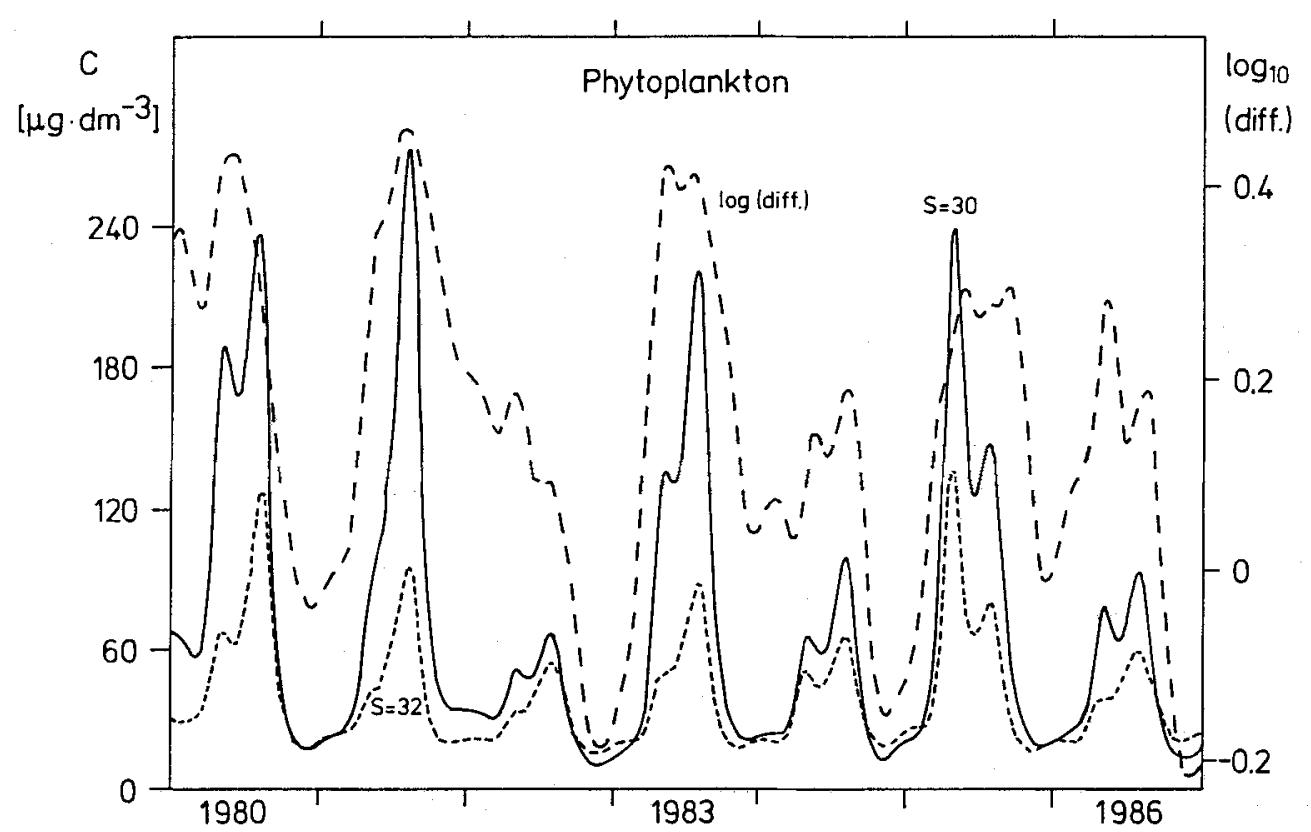

Fig. 4. Helgoland Roads 1980-1986: phytoplankton stock for $S=30$ and for $S=32$ and the difference (diff.) of the logarithms of these two values

\section{RESULTS}

The environment does not directly influence the plankton stock but it does influence its growth rate. As a consequence, the first derivative with respect to time has to be determined and compared with other components'(Fig. 5). The small daily increases or decreases of the stocks (up to $4 \%$ ) can be seen; but it must be remarked that in this special case a "high frequency" fluctuation of the diatoms has been filtered off to give a reasonable figure. These disturbances may have something to do with the residual current and its consequences (Gillbricht, 1983). In this way, different populations pass Helgoland so periodically as to be described by the smoothing method as a cyclic function. The resulting effect is more pronounced in the case of the (relatively) fast growing diatoms in contrast to the flagellates.

These derivatives are to be compared with the equations for the annual cycles of the sun, the temperature as an indicator of stability and, in spite of former investigations (Gillbricht, 1988), the (inorganically bound) nutrients (P, N). Lacking similar observations, other components could not be considered, e. g. special (meteorological) events, zooplankton.

Measurement of the vertical turbulence is a difficult task. Stratification cannot be determined under the local conditions and, in this shallow channel with strong tidal currents, is certainly not representative of the region as a whole. So an attempt was made to use the daily warming-up process of the water as a stabilizing effect. This method needs the inclusion of the second derivative (i. e. the daily changes in the warming-up process) as a further indicator. But there is one more problem: the anomaly of water 


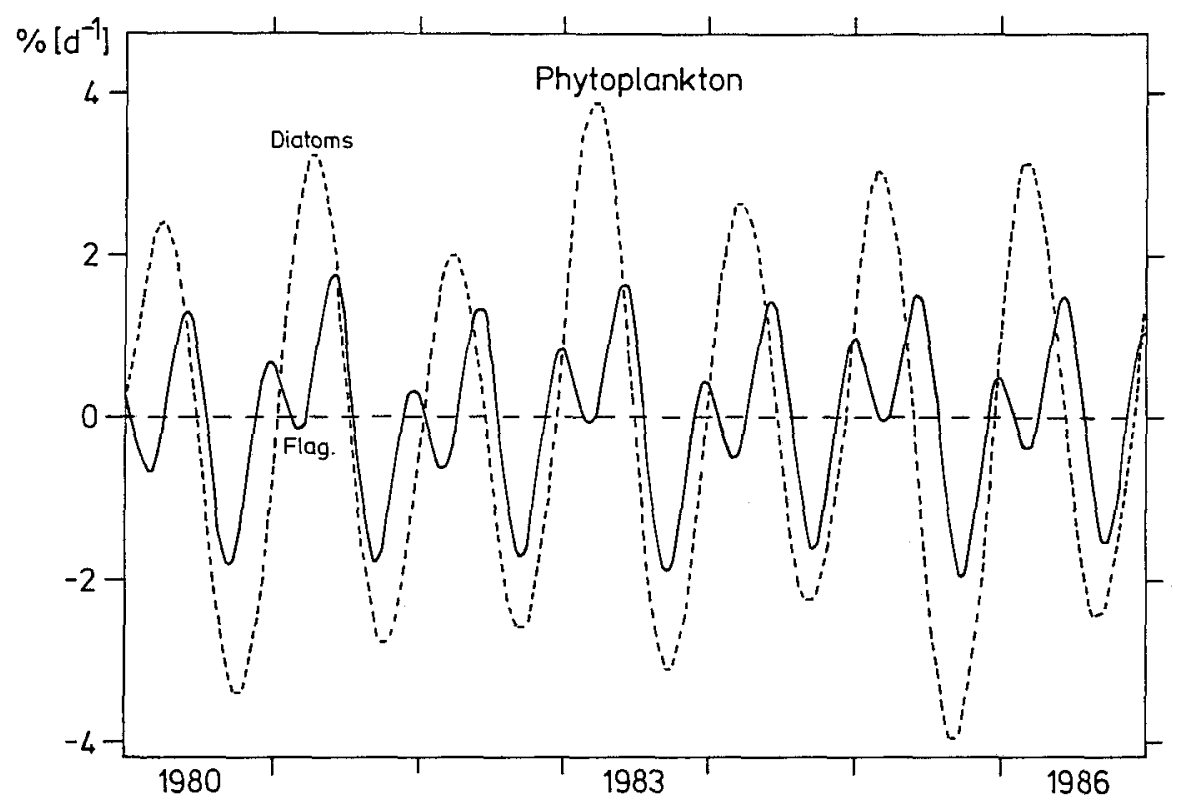

Fig. 5. Helgoland Roads 1980-1986: daily increase (\%) of the stocks of flagellates and diatoms; $\mathrm{S}=31$; diatoms (corrected) $: \mathrm{N}=1830 ; \mathrm{R}=0.668$

produces different density effects by warming-up at different temperatures (Fig. 6; Anonymous, 1981). A corresponding correction may be included in the calculations.

If we compare the primarily calculated formulae, we observe phase-shifted sinusoidal functions with a preference wave length of approximately one year. It is therefore difficult to work out the best description of (logarithmic) phytoplankton growth by one or more other equations under the aspect of causality, without selecting with prejudice. Thus, for instance, a good - but not the best - illustration of the flagellate development shows that the latter is negatively correlated with light and phospate, a result so far beyond our knowledge that it certainly cannot have anything to do with causality but rather with the phosphorus dynamics (Gillbricht, 1988). Furthermore, another reasonable description gives positive (partial) correlations between growth of the flagellates and the warming-up process of water together with the sum of the inorganic nitrogen compounds. This latter finding may not be right with respect to causality when one bears in mind the situation in this and other regions, the nutrient cycle in the sea (Gillbricht, 1988), and the fact that the flagellates clearly demonstrate two growth periods during the year (Fig. 5). A separate investigation of both time-spans shows no nutrient dependence in summer; and the discharge of phosphate in winter runs parallel with the increasing growth of the flagellates. This result indicates that our countings may include optional and/or obligatory heterotrophic forms.

These problems with the evaluation can be overcome by an expensive treatment of the material. From the different equations a new data set was calculated step by step and then an attempt was made to find out the connections between the phytoplankton and its environment. The best solution was detected by starting with the description of growth 


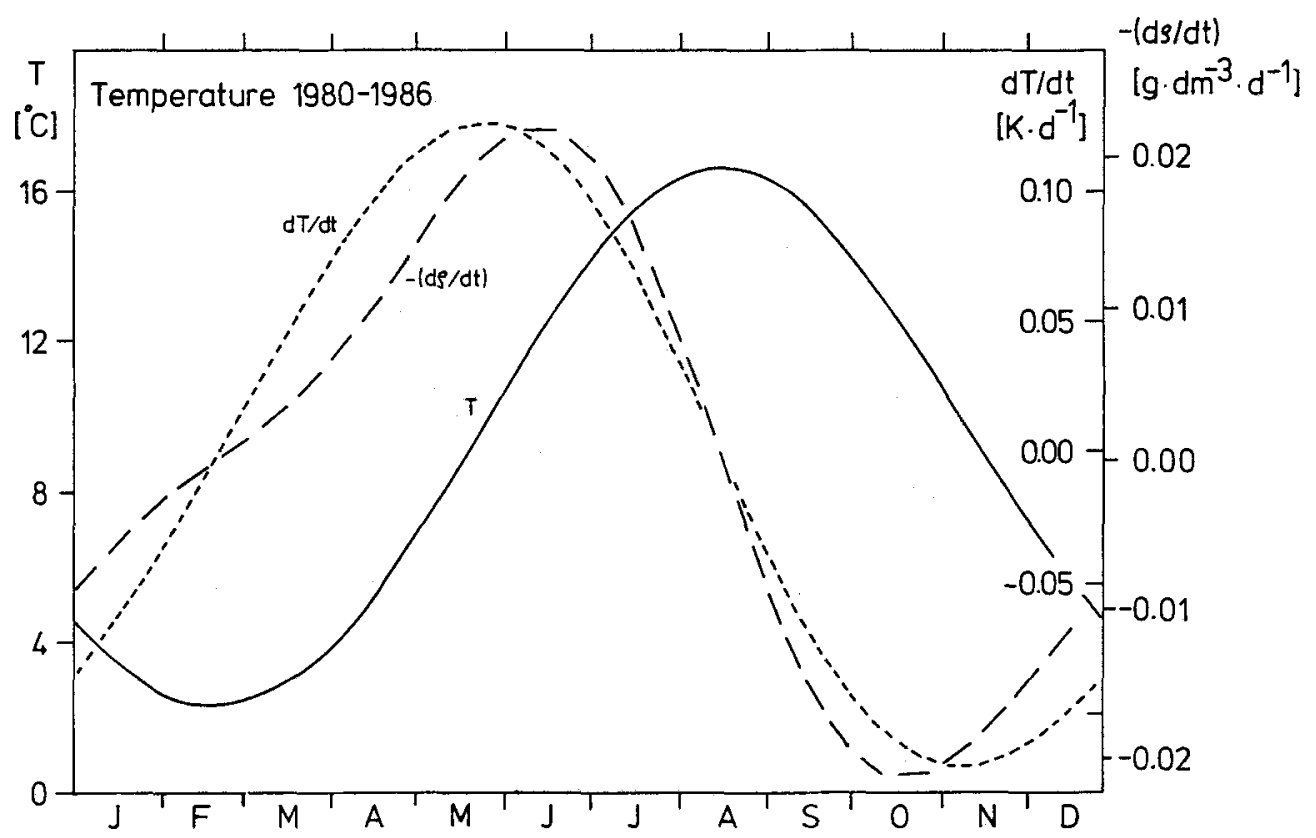

Fig. 6. Helgoland Roads, annual mean curves 1980-1986; temperature ( $T$ ); daily increase of the temperature $(\mathrm{dT} / \mathrm{dt})$ and its density effect $-(\mathrm{d} \rho / \mathrm{dt}) ; \mathrm{S}=31 ; \mathrm{N}=1827 ; \mathrm{R}=0.991$

for the respective phytoplankton group as a (linear) function of all environment factors observed. This procedure was repeated after the elimination of the most negligible component (partial correlation) and ended only when highly significant terms remained. The result of this procedure was a simple one. All three functions (flagellates, diatoms, and diatoms corrected with respect to short-term fluctuations) were optimized by using the warming-up process of water, and the respective second derivative, with a density correction (anomaly of the water) for the flagellates; in this way, the direct influence of the sun's annual cycle was also, in some way, included.

Under these conditions, it is possible to describe the stocks (the integrals) in the same way. Thus, the mean annual cycle of the phytoplankton can be formulated reasonably by derivatives of the temperature (Fig. 7). In contrast to this finding, the description of the course of plankton for the total period is not at all satisfying (Fig. 8). The situation regarding temperature is too similar from year to year. This observation can be expected to have something to do with the exponential distribution and with different gradients with respect to salinity at different times (Fig. 4). This can be demonstrated by a comparison of two factors: the logarithmic plankton difference $[\log$ (measured)-log(calculated by temperature)] with the logarithmic (negative) derivative with respect to salinity (Fig. 9). This finding gives the impression that the development of the phytoplankton stock is influenced by mixing processes. Here, only the flagellates are used, because the more unevenly distributed diatom population is confusing in its behaviour.

This problem can be investigated for flagellates and diatoms. The first approximation, in a simple way, is the assumption that two water masses mix together in an equal volume (correctly termed equal weight): 


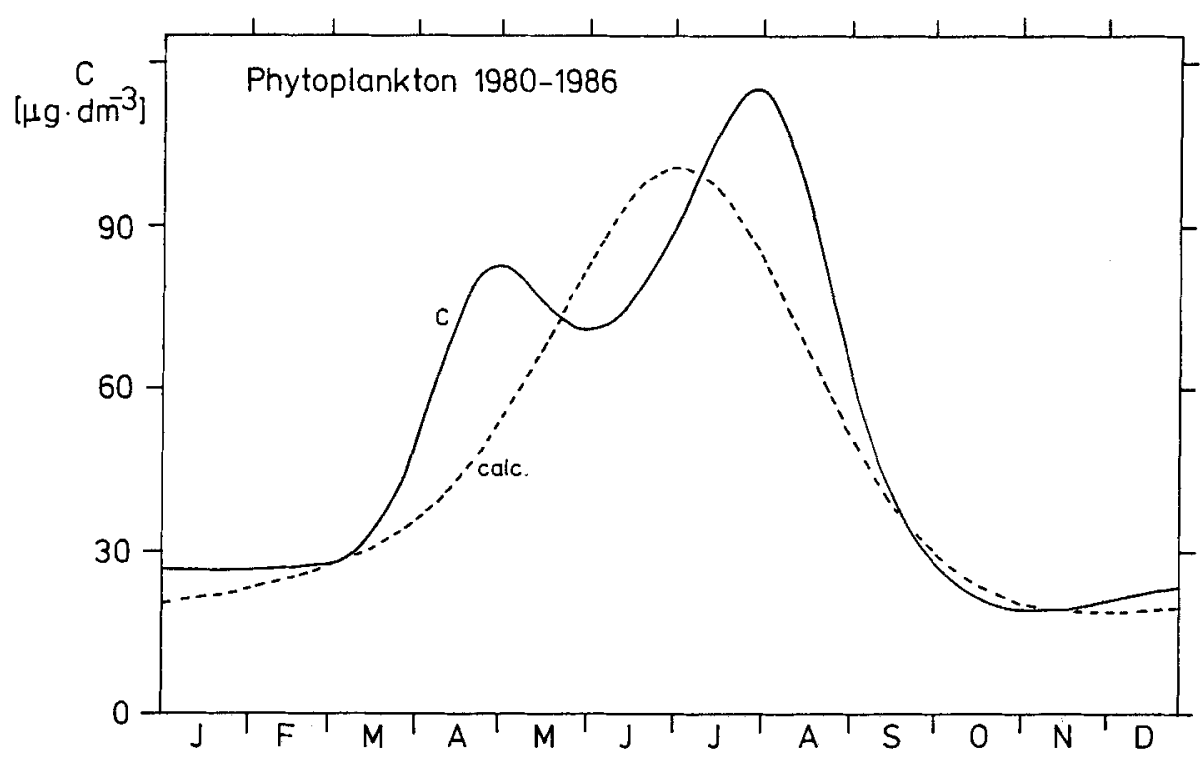

Fig. 7. Helgoland Roads, annual mean curves 1980-1986: phytoplankton stock (C) and calculated (calc.) by means of derivatives of the temperature; $S=31$

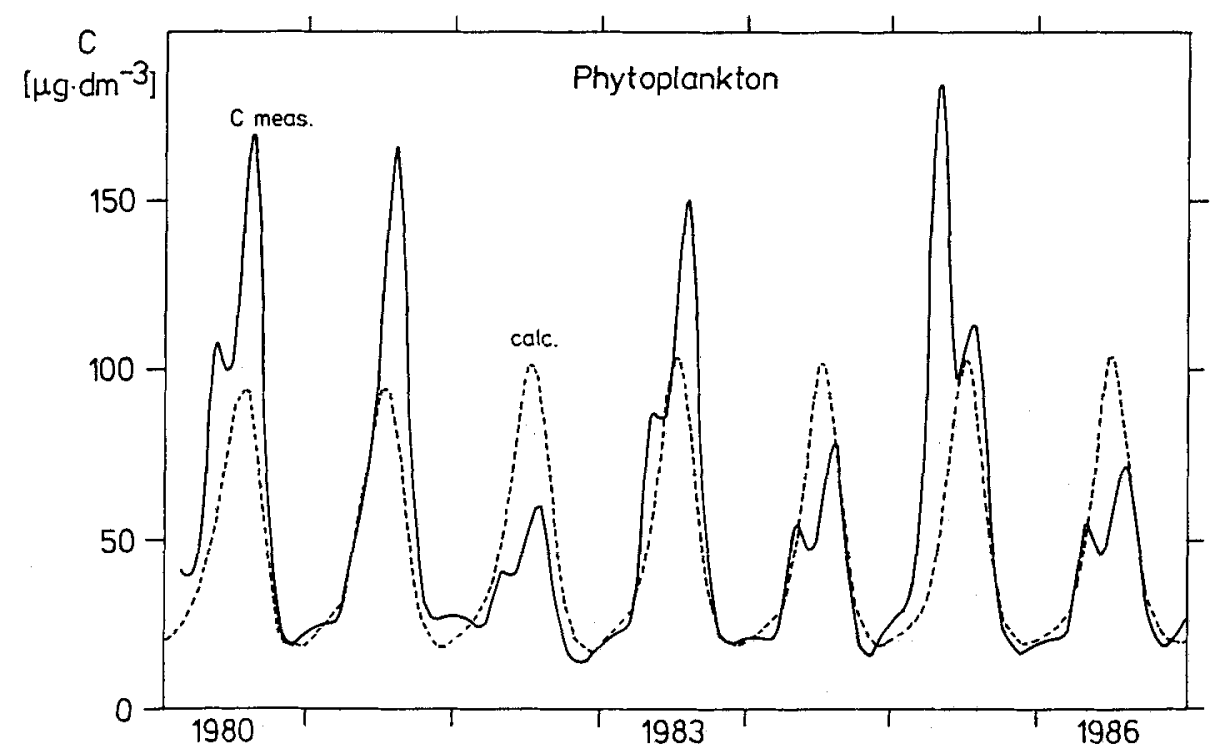

Fig. 8. Helgoland Roads 1980-1986: phytoplankton stock (C) and calculated (calc.) by means of derivatives of the temperature; $S=31$

(1) The plankton content is calculated from the temperature (numerical scale; $\mathrm{S}=$ 31 ), and this calculation is approximated anew in connection with (3).

(2) Two equidistant (with respect to salinity) waters are mixed, thus getting also $\mathrm{S}=$ 31 but with a larger plankton content than directly observed (logarithmic gradient). 


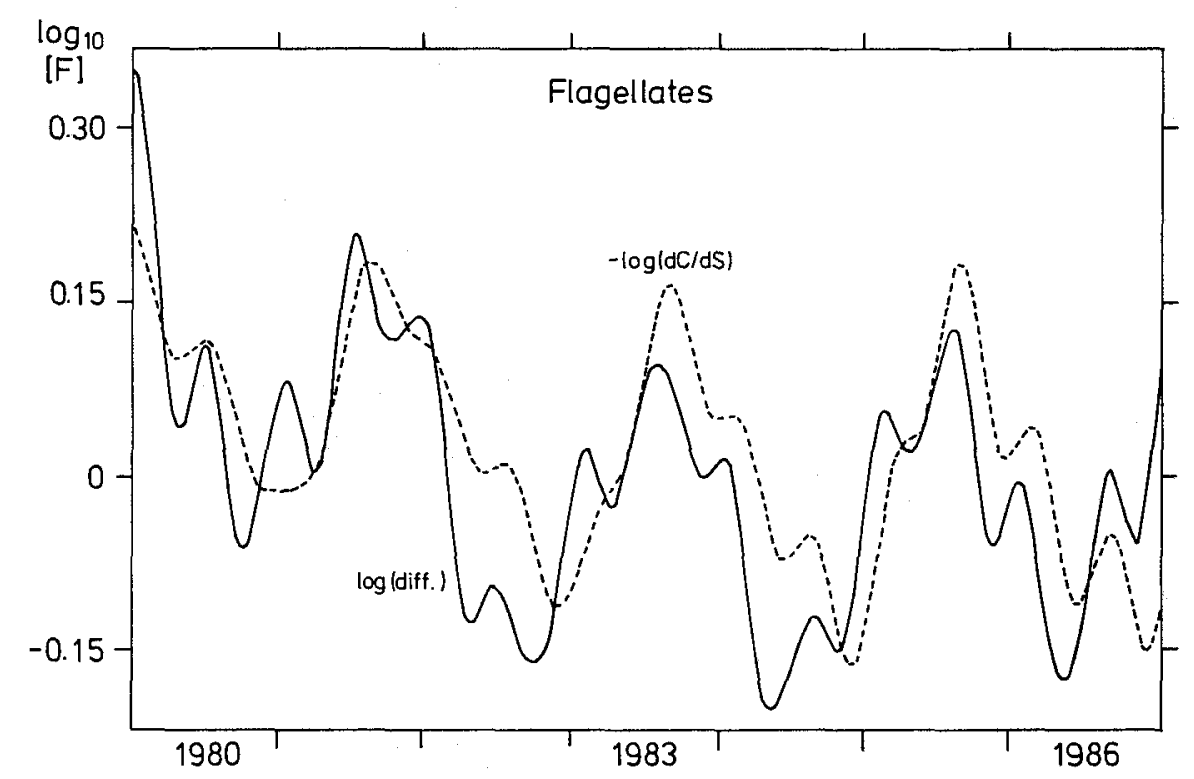

Fig. 9. Helgoland Roads 1980-1986; flagellates: factors (F): $\log ($ stock)-log(calc. by temp.) (diff.) and $\log$ (salinity gradient of stock) $-(\mathrm{dC} / \mathrm{dS}) ; \mathrm{S}=31$

(3) The mean salinity distance for the total course is to be optimized (sum of squares) in such a way that a mixture of (1) and (2) gives the plankton content as observed. The calculation is made by means of the differential quotient $(\mathrm{dC} / \mathrm{dS})$ for the flagellates. In the case of the more complicated diatom distribution, the respective difference quotient $(\Delta \mathrm{C} /$ $\Delta \mathrm{S}$ ) is necessary. Realistic salinity distances are achieved with this primitive method.

The result of this consideration is given in Figure 10. From a statistical point of view this procedure is a little dubious, but how do these plankton stocks, which differ in size from year to year indicating different growth conditions, arise? We must assume that in this area the horizontal salinity gradient increases with decreasing salinity. This means the centre of a mixing zone is located nearer the coast. The situation is the same with the density gradient and, therefore, with the resulting density-induced current and, as a consequence, with the vertical stability. Additionally, a high vertical turbulence exists alongside a system of upwellings and downwellings and is produced by coast-parallel tidal currents, Coriolis force and bottom friction. Of special interest is the curve giving the logarithms of the proportion between two "populations" (Fig. 4). Here, the (relative) gradient between both values can be seen to fluctuate more or less parallel to the stock. This fact may be correlated, in some way, with the variation of the structure and of the position of the front between the coastal water and that of the North Sea. This further meteorological effect calls attention to longer lasting fluctuations of the stocks (at least) in the same range as observed during this investigation in connection with climatic variations (Dickson, 1971).

On the basis of these last findings, it can be stated that the low growth rates observed (see above) are also a product of admixture. In this case, the phytoplankton is transported by turbulence from a zone nearer the coast out to the open sea. 


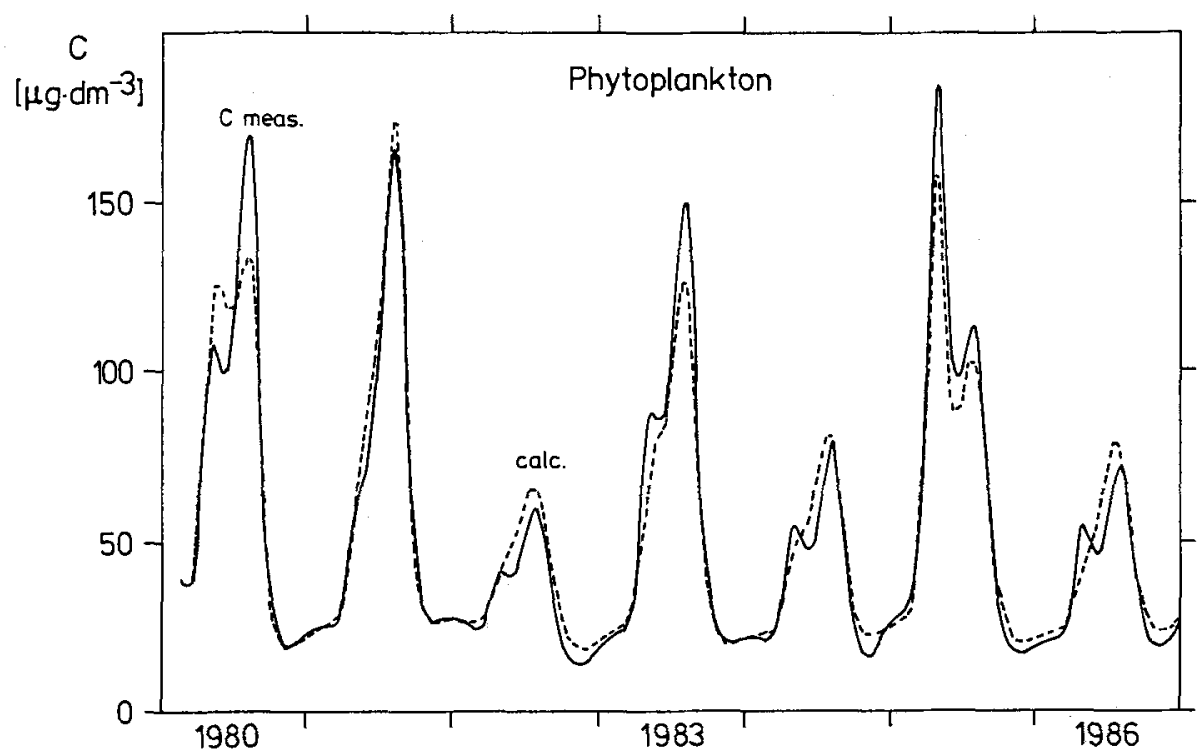

Fig. 10. Helgoland Roads 1980-1986: phytoplankton stock (C) and calculated by means of derivatives of the temperature and by mixing processes (calc.); $\mathrm{S}=31$

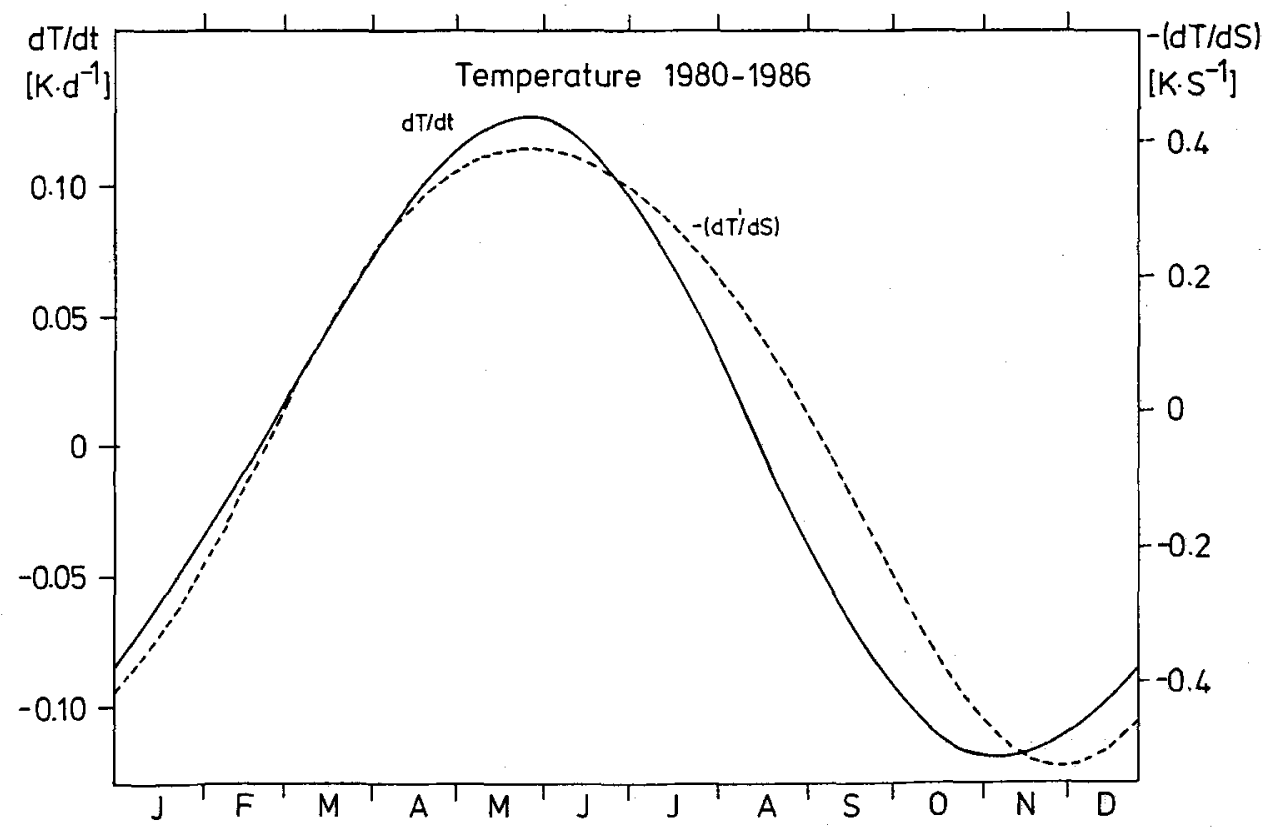

Fig. 11. Helgoland Roads, annual mean curves 1980-1986: daily increase of the temperature (dT/dt) and salinity gradient of the temperature $-(\mathrm{dT} / \mathrm{dS}) ; \mathrm{S}=31$ 


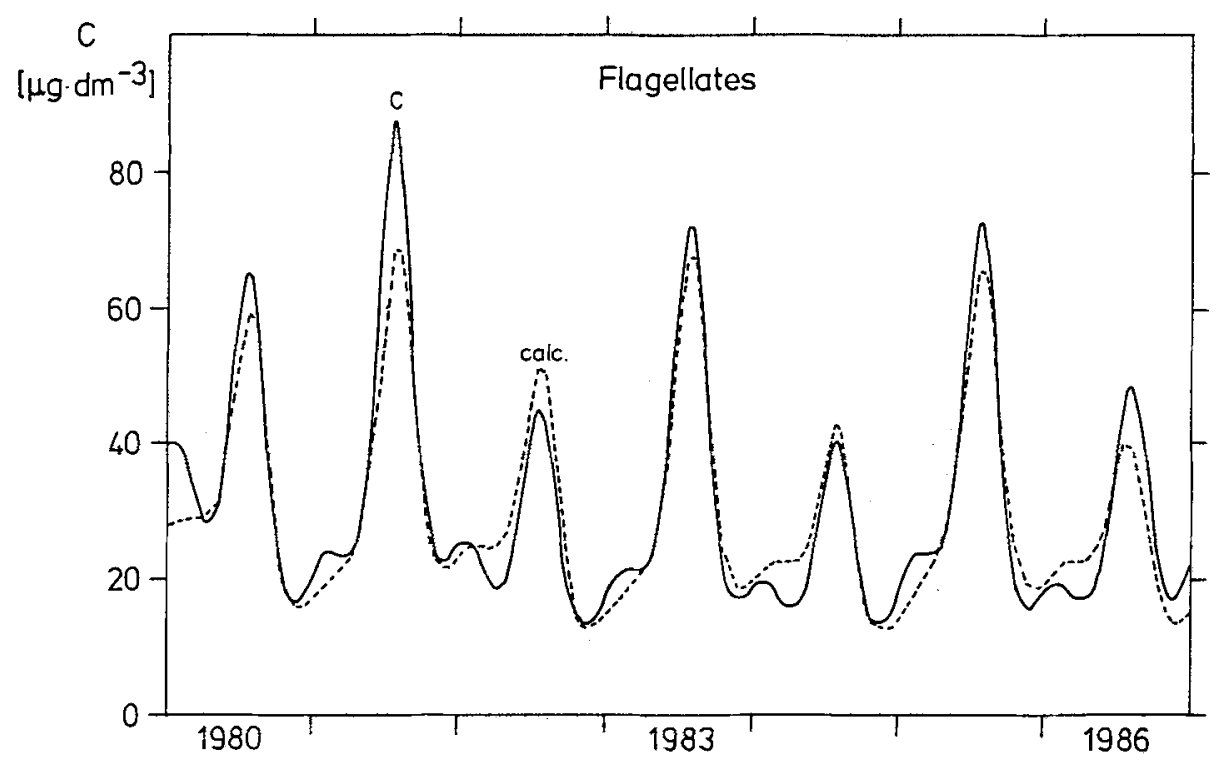

Fig. 12. Helgoland Roads 1980-1986: stock of flagellates (C) and calculated (calc.) by means of its derivative with respect to salinity and by means of derivatives of the temperature; $\mathrm{S}=31$

These facts suggest that a better description of the phytoplankton stock by temperature should be possible by inclusion of the derivative with respect to salinity. This method does not work, because both this derivative and that with respect to time are nearly identical with respect to the annual course (Fig. 11). Both influences are therefore already considered and both indicate that, in winter, the cooling of the water and the increase of the temperature with the salinity counteract any stabilization of the water column. During the rest of the year this system.permanently retains a certain stratification, in spite of the turbulent tidal currents and also in the case of special events, allowing in this way a moderate growth rate of the phytoplankton over a long time-span, but under very vulnerable conditions because the losses almost equal the production.

One possibility exists for a better representation of the reasonably evenly distributed flagellates. These organisms may be described by their own derivative with respect to salinity and by derivatives of the temperature (Fig. 12).

It may be difficult to gain better information on these problems from a single vantage point. Therefore, there is need for more measurements in the region, diversified in space and time, and for more investigations on the evaluation techniques best suited to gain more understanding of this complicated transition zone.

Acknowledgements. I am particularly grateful to the late Prof. Dr. A. Bückmann, who made the interesting investigation in the harbour basin possible. Dr. W. Hickel and G. Delfs helped with the drawings; and C. Berger improved the English text. 


\section{LITERATURE CITED}

Anonymous, 1981. Tenth report of the joint panel on oceanographic tables and standards. The practical salinity scale 1978 and the international equation of state of seawater 1980. - Unesco tech. Pap. mar. Sci. 36, 13-21.

Brandt, K., 1899. Ueber den Stoffwechsel im Meere. - Wiss. Meeresunters. (Kiel) 4, 213-230.

Brandt, K., 1902. Ueber den Stoffwechsel im Meere. 2. Abhandlung. - Wiss. Meeresunters. (Kiel) 6 , $23-79$.

Dickson, R. R., 1971. A recurrent and persistent pressure-anomaly pattern as the principal cause of intermediate-scale hydrographic variation in the European shelf seas. - Dt. hydrogr. Z. 24, 97-119.

Gillbricht, M., 1955. Wucherungen von Phytoplankton in einem abgeschlossenen Hafenbecken. Helgoländer wiss. Meeresunters. 5, 141-168.

Gillbricht, M., 1962. Die Frühjahrswucherung des Phytoplanktons in einem flachen Gezeitenmeer. Kieler Meeresforsch. 18, 151-156.

Gillbricht, M., 1983. Eine "red tide" in der südlichen Nordsee und ihre Beziehungen zur Umwelt. Helgoländer Meeresunters. 36, 393-426.

Gillbricht, M., 1988. Phytoplankton and nutrients in the Helgoland region. - Helgoländer Meeresunters. $42,435-467$.

Gran, H. H. \& Braarud, T., 1935. A quantitative study of the phytoplankton in the Bay of Fundy and the Gulf of Maine (including observations on hydrography, chemistry and turbidity). - J. biol. Bd Can. 1, 279-467.

Radach, G. \& Bohle-Carbonell, M., 1990. Strukturuntersuchungen der meteorologischen, hydrographischen, Nährstoff- und Phytoplankton-Langzeitreihen in der Deutschen Bucht bei Helgoland. - Ber. Biol. Anst. Helgoland 7, 1-425.

Sverdrup, H. U., 1953. On conditions for the vernal blooming of phytoplankton. - J. Cons. perm. int. Explor. Mer 18, 287-295. 